\title{
Kajian Pertumbuhan Awan Hujan Pada Saat Banjir Bandang Berbasis Citra Satelit dan Citra Radar (Studi Kasus: Padang, 2 November 2018)
}

\author{
Abdul Hamid Al Habib*, Yoga Wahyu Pradana, Dany Pangestu, Paulus Agus Winarso, \\ dan Jusa Sujana \\ Sekolah Tinggi Meteorologi Klimatologi dan Geofisika \\ *Email : abdulhamidalhabib96@gmail.com
}

\begin{abstract}
ABSTRAK
Banjir besar kembali melanda enam kecamatan di kota Padang, Sumatera Barat pada tanggal 2 November 2018. Banjir terjadi disebabkan oleh debit sungai yang meluap akibat hujan sangat lebat yang terjadi di bagian hulu dan hilir. Dampak banjir bandang tersebut mengakibatkan 600 rumah terendam banjir, 3 jembatan putus dan menelan korban jiwa. Karena dampak tersebut maka penelitian ini dilakukan untuk meninjau kondisi suhu permukaan laut, mean sea level pressure, nilai transport uap air, streamline, data citra satelit Himawari-8 dan data citra radar cuaca $C$-Band. Data diolah dalam bentuk grafik dan peta spasial kemudian dilakukan analisis deskriptif yang meliputi analisis temporal dan analisis spasial. Berdasarkan hasil analisis hujan sangat lebat yang terjadi di wilayah Padang dipicu oleh gangguan cuaca skala regional berupa adanya pola shearline atau komponen zona arah lintasan angin yang mengalami perubahan secara tiba-tiba yang sejajar dengan angin horizontal dan daerah tekanan rendah yang menimbulkan konvergensi di pesisir kota Padang, kemudian nilai transport uap air yang cukup tinggi yaitu kisaran antara 700-1100 $\mathrm{Kg}_{\mathrm{ms}}^{-1}$ pada lapisan 1000-300 mb. Terjadinya hujan lebat seringkali terkait dengan keberadaan awan Cumulonimbus ( $\mathrm{Cb}$ ). Hal ini dikarenakan karakteristik awan $\mathrm{Cb}$ dengan dimensi yang besar serta mengandung banyak partikel presipitasi seperti air dan kristal es. Kondisi ini didukung dengan keberadaan awan $\mathrm{Cb}$ berdasarkan analisis time series citra satelit Himawari-8 dan nilai reflektifitas radar berada pada nilai 45-60 dBz. Pada tanggal 2 November 2018, hampir seluruh awan hujan yang muncul mempunyai ketebalan lebih dari $7 \mathrm{~km}$, dimana suhu puncak awan terendah mencapai nilai $\quad-72.5^{\circ} \mathrm{C}$.
\end{abstract}

Kata Kunci : hujan sangat lebat, citra satelit Himawari, citra radar cuaca, awan cumulonimbus

\begin{abstract}
A massive flood again hit six sub-districts in the city of Padang, West Sumatra on November 2, 2018. Floods were caused by river debris which overflowed due to heavy rainfall that occurred in the upstream and downstream. The impact of the flash floods caused 600 houses to be flooded, 3 bridges broke up and claimed lives. Because of this impact, this research was conducted to review the condition of sea surface temperature, mslp, water vapor transport value, streamline, Himawari-8 satellite and C-Band weather radar image data. The data was processed in the form of graphs and spatial maps then descriptive analysis was carried out which included temporal analysis and spatial analysis. Based on the results of the analysis, regional weather disruption in the form of a shearline pattern or component of the direction of the wind trajectory that changes suddenly which is parallel to horizontal wind and low pressure areas that cause convergence in the coastal city of Padang, then the value of water vapor transport is quite high,

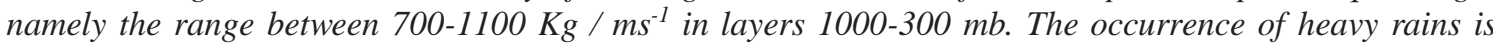
often related to the presence of Cumulonimbus $(\mathrm{Cb})$ clouds. This is due to the characteristics of $\mathrm{Cb}$ clouds with large dimensions and contain many particles of precipitation such as water and ice crystals. This condition is supported by the presence of $\mathrm{Cb}$ cloud based on the analysis of the Himawari-8 time series satellite images and the radar reflectivity value at a value of 45-60 dBz. On November 2, 2018, almost all of the rain clouds that appeared had a thickness of more than $7 \mathrm{~km}$, where the lowest cloud peak temperature reached a value of $-72.5^{\circ} \mathrm{C}$.
\end{abstract}

Keyword: Very Heavy Rain, Himawari Satellite Image, Weather Radar Image, Cumulonimbus Cloud 


\section{PENDAHULUAN}

Wilayah Indonesia merupakan negara kepulauan yang dilalui oleh garis ekuator geografis (lintang $0^{\circ}$ ), hal ini menyababkan Indonesia menjadi daerah dengan surplus energi, dimana cuaca di Indonesia didominasi oleh awan dan hujan konvektif. Awan jenis Cumuliform yaitu Cumulus dan Cumulonimbus menyebabkan hujan deras lokal akibat konveksi yang berada dalam udara labil;intensitas hujan besar, dari hujan biasa sampai hujan deras (shower). Arus udara ke atas (updraft). dalam awan ini mencakup daerah kecil tapi kuat. Jenis Cumuliform, terutama awan Cumulonimbus, dapat menghasilkan batu es hujan (hail stone), guruh dan kilat (Tjasyono, 2008).

Hujan lebat yang dihasilkan oleh awan-awan jenis Cumuliform akan menjadi bencana apabila curah hujan dengan intensitas tinggi dan durasi lama meluap pada daerah aliran sungai (DAS), yaitu disebut fenomena bencana banjir bandang. Bencana banjir merupakan salah satu bencana alam, yang menyebabkan korban jiwa dan kerugian ekonomi yang besar. Kerusakan lingkungan, perubahan fisik permukaan tanah menyebabkan penurunan daya tampung dan daya simpan air hujan, sehingga sebagian besar curah hujan dilarikan sebagai air limpasan (runoff) yang sangat berpotensi menjadi bencana banjir (Nababan, 2014). Bencana banjir yang terjadi di wilayah Padang, Sumatra Barat pada tanggal 2 November 2018 telah menyebabkan 2 warga meninggal dunia serta 600 rumah terendam banjir, 3 jembatan putus (detik.com, 2018). Apabila melihat kejadian ini perlu dilakukan analisis untuk mengetahui penyebab kejadian hujan lebat yang berdampak banjir pada tanggal 2 November 2018, dengan melihat karakteristik awan dan hujan pada sebelum, saat dan sesudah kejadian.

Salah satu Instrumen yang dapat digunakan untuk mengidentifikasi awan konvektif adalah radar cuaca. Radar menjadi contoh penginderaan jauh untuk mengukur objek di atmosfer bumi dengan sebuah jarak (Schowengerdt, 2006). Radar cuaca dapat mengamati dan memberikan informasi cuaca untuk area pengamatan yang luas secara real time dan kontinu, sehingga dapat dimanfaatkan untuk peringatan dini terhadap cuaca ekstrem.

Peringatan dini terbentuknya awan cumulonimbus dapat didukung oleh Satelit Himawari-8. Satelit Himawari-8 merupakan satelit cuaca meteorologi geostasioner yang merupakan generasi penerus satelit MTSAT 2 yang diluncurkan pada tahun 2015 oleh JMA yang berfungsi untuk mengamati parameter meteorologi misalnya untuk mengamati perkembangan awan cumulonimbus. Satelit himawari-8 memiliki 16 kanal yang terdiri dari Visibel, Near-IR, IR WV (Water Vapour), SW IR, dan LW IR. Satelit Himawari-8 menyediakan pengamatan setiap 10 menit sehingga dapat memberikan atau menggambarkan perkembangan fenomena meteorologi seperti awan cumulonimbus secara komprehensif (Mahfiroh, 2017).

Jurnal ini ditulis dengan sistematika pendahuluan, berisi mengenai penjelasan tentang latar belakang, tujuan dan manfaat penelitian, serta sistematika penulisan, lalu data dan metode berisi prosedur penelitian dan diagram alir. Hasil penelitian, berisi penjelasan, analisis, dan pembahasan hasil penelitian ini. Terakhir kesimpulan, berisi tentang kesimpulan secara keseluruhan dari penelitian ini, saran untuk penelitian selanjutnya, ucapan terimakasih, dan daftar pustaka.

\section{DATA DAN METODE}

Penelitian ini mengambil daerah studi di wilayah Kota Padang dan sekitarnya dengan mengambil koordinat $0^{0} 57^{\prime} 0^{\prime}$ 'S $100^{\circ} 21$ ' 11'BT. (Gambar 1)

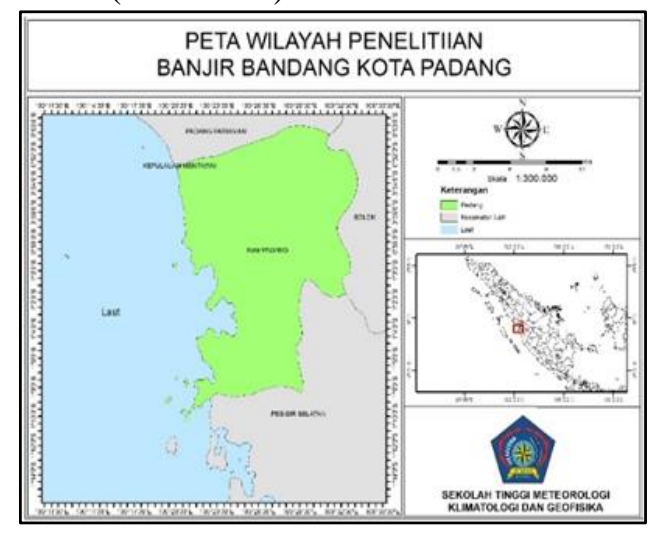

Gambar 1. Lokasi penelitian. 
Data yang digunakan dalam penelitian ini merupakan data citra radar, data citra satelit dan data re-analisis ECMWF. Data radar cuaca diakses dari radar polarisasi tunggal dari Stasiun Meteorologi Padang pada tanggal 2 November 2018. Metode operasional radar cuaca Stasiun Meteorologi Padang saat penelitian mengggunakan Volume Coverage Pattern (VCP) 21 yang memiliki 11 elevasi, yaitu dari $0,50^{0}$ hingga $19,50^{\circ}$. Pulse Repetition Frequency (PRF) yang digunakan nilainya bervariasi dari 600 $800 \mathrm{~Hz}$ dan jangkauan data (range) yang akan dimanfaatkan adalah pada radius 3-150 $\mathrm{km}$, disesuaikan dengan waktu dan lokasi penelitian. Produk yang digunakan adalah produk Column Maximum (CMAX) digunakan untuk melihat nilai reflektivitas awan konvektif dan produk Vertical Cut (VCUT) digunakan untuk menampilkan sebuah irisan tegak lurus dari suatu polar volume set dan dapat meninjau pola updraft dan downdraft yang terjadi pada awan konvektif (Wardoyo, 2011).

Raw data satelit Himawari-8 dapat diakses melalui ftp://satelit.bmkg.go.id. Raw data satelit Himawari-8 yang digunakan adalah kanal 13 dan 15, dengan format sataid yang memiliki resolusi temporal tiap 10 menit untuk menampilkan produk peringatan dini cuaca signifikan dari awan $\mathrm{Cb}$ (BMKG, 2016). Kanal IR digunakan untuk melihat suhu puncak awan dan untuk analisis pembentukan awan pada kejadian di Padang tanggal 2 November 2018. Raw data satelit diolah dengan menggunakan software GMSLPD. Hasil pengolahan ini berupa citra suhu puncak awan secara spasial dengan satuan derajat Celcius $\left({ }^{\circ} \mathrm{C}\right)$, guna melihat perkembangan suhu puncak awan selama 24 jam di wilayah penelitian. Selain untuk melihat suhu puncak awan, hasil pengolahan ini juga untuk analisis pembentukan awan dan untuk melihat kontur awan (BMKG, 2014).

Data Reanalisis ERA Interim pada bulan November 2018 dengan resolusi $0,125^{\circ} \mathrm{x}$ $0,125^{\circ}$ dalam bentuk Network Common Data Form (netCDF). Data tersebut diakses secara interaktif melalui alamat https://apps. ecmwf.int/datasets/data/interim-full-daily, meliputi: streamline, transport uap air, sea surface temperature dan mean sea level pressure. Aplikasi Grads digunakan untuk mengolah dan menampilkan data Reanalisis ERA Interim dari Europian Center Medium Range Weather Forecast (ECMWF) tersebut. Metode yang digunakan dalam penelitian ini adalah metode deskriptif analitis baik pada hasil tampilan citra satelit, citra radar maupun model ECMWF. Setelah data diolah, maka analisis data dilakukan dengan metode life history. Metode life history digunakan untuk menjelaskan waktu tahapan pertumbuhan awan konvektif. Perkembangan awan konvektif dapat dilihat secara rinci dengan memerhatikan waktu hidup per fase dan pergerakannya dari koordinat sel. Model ECMWF menjadi pedoman untuk menggambarkan kondisi dinamis atmosfer.

\section{HASIL DAN PEMBAHASAN}

\subsection{Kondisi SST dan MSLP}

Sea Surface Temperature dan Mean Sea Level Pressure Perairan Sumatera Barat merupakan salah satu parameter untuk mendukung pertumbuhan awan konvektif. Terlihat di wilayah pembentukan awan konvektif, yakni perairan Sumatera Barat menunjukkkan suhu permukaan laut sebesar $31^{\circ} \mathrm{C}$. Dari data MSLP tekenan terendah terjadi pada pukul 21.00 UTC sebesar $1009,5^{0} \mathrm{mb}$ dengan pusat tekanan rendah di periaran Sumatera Barat pesisir kota Padang. Dilihat dari kerapatan isobar, maka dapat disimpulkan semakin rapat garis isobar ke daerah tekanan rendah, menunjukkan gradien tekanan yang cukup besar. Hal tersebut mengakibatkan pergerakan massa udara ke daerah pusat pertumbuhan awan konvektif.

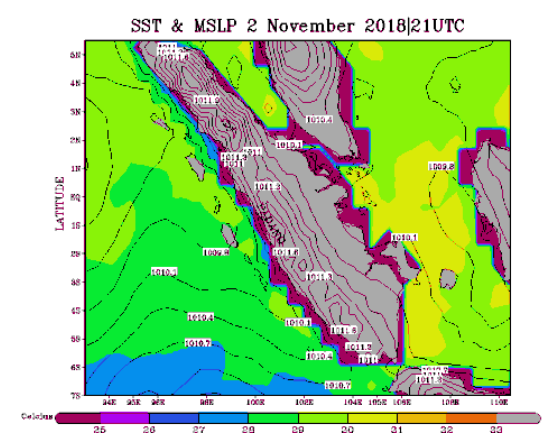

Gambar 2. Sea Surface Temperature dan Mean Sea Level Pressure 


\subsection{Analisis kondisi angin}
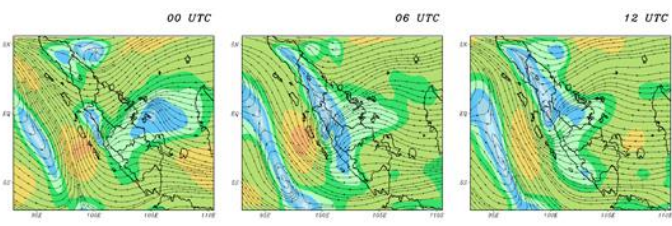

o3 urc
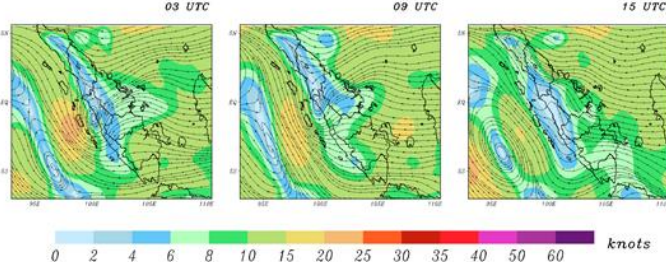

Gambar 3. Streamline Angin Lapisan 3000 feet 2 November 2018

Berdasarkan gambar streamline angin lapisan 3000 feet diidentifikasi angin bertiup dari arah Timur dengan kecepatan angin 10-20 knot, terdapat gangguan cuaca berupa belokan angin dan konvergensi tepat di kota Padang. Hal tersebut berpotensi memberikan dampak pada pertumbuhan awan hujan khususnya awan cumulonimbus di wilayah Padang. Pola

konvergensi di wilayah Padang berlangsung dari pukul 00.00 UTC-12.00 UTC, sedangkan pukul 15.00 UTC pola konvergensi tersebut telah bergeser ke arah barat menjauhi kota Padang. Kecepatan angin tertinggi yaitu 25 knots terjadi pada pukul 00.00 UTC-06.00 UTC. Mulai pukul 09.00 UTC kecepatan angin semakin rendah.

\subsection{Kondisi transport uap air}
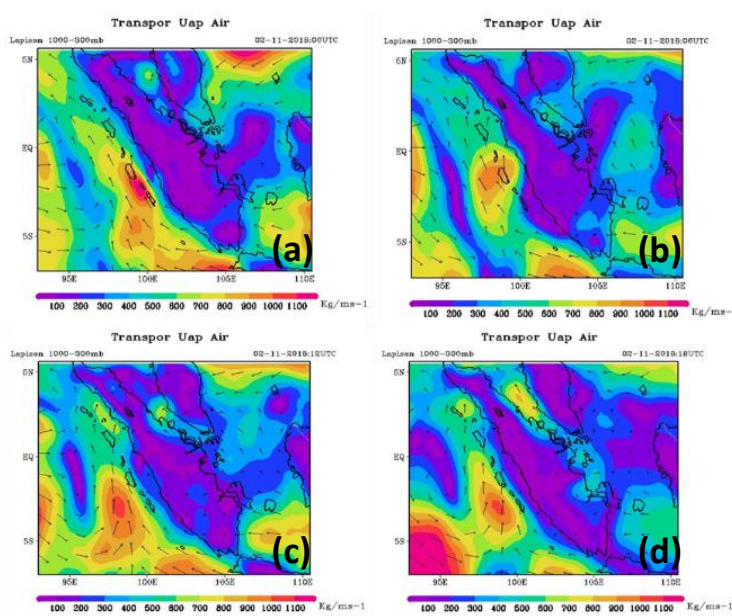

Gambar 4. Transpor uap air tanggal 2 November 2018. (a) pukul 00 UTC, (b) pukul 06 UTC, (c) pukul 12 UTC, (c) pukul 18 UTC

Berdasarkan gambar diatas transpor uap air di pesisir kota Padang, Sumatera Barat pada tanggal 2 November 2018 kandungan transpor uap air di lapisan 1000-300 mb sebesar 700-1100 Kg/ms $\mathrm{ms}^{-1}$. Nilai transpor uap air maksimum di dinding pusat tekanan rendah. Pergerakan massa transpor uap air dari arah Timur dan Barat yang kemudian terakumulasikan di pesisir kota Padang, Sumatera Barat.

\subsection{Analisis Citra Satelit}
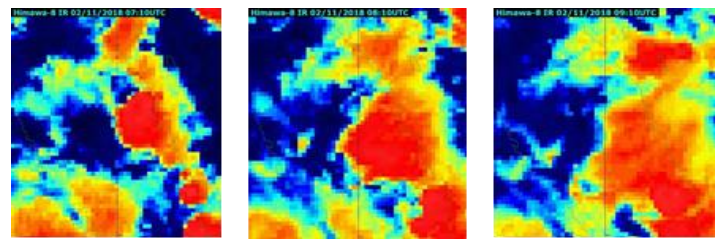

Gambar 5. Citra Satelit Himawari-8 kanal IR pukul 07.10-09.10 UTC pada tanggal 2 November 2018

Berdasarkan gambar diatas, pada pukul 07.10 UTC terlihat pola merah padat mengumpul di pesisir kota padang, hal ini menunjukkan kuatnya aktivitas konvektif sehingga terbentuk awan awan konvektif di wilayah tersebut. Pada fase ini disebut fase pertumbuhan awan. Pada pukul 08.10 UTC pola merah mulai menyebar di sepanjang perairan kota padang dengan warna merah padat dengan dikelilingi warna kuning, hal ini menunjukkan fase awan sudah matang dan siap terjadi presipitasi di wilayah tersebut. Pada pukul 09.10 UTC terlihat pola warna merah padat mulai memudar, hal ini menunjukkan tahap punah awan konvektif di wilayah tersebut.

\subsection{Analisis Contour dan Time Series Citra Satelit}

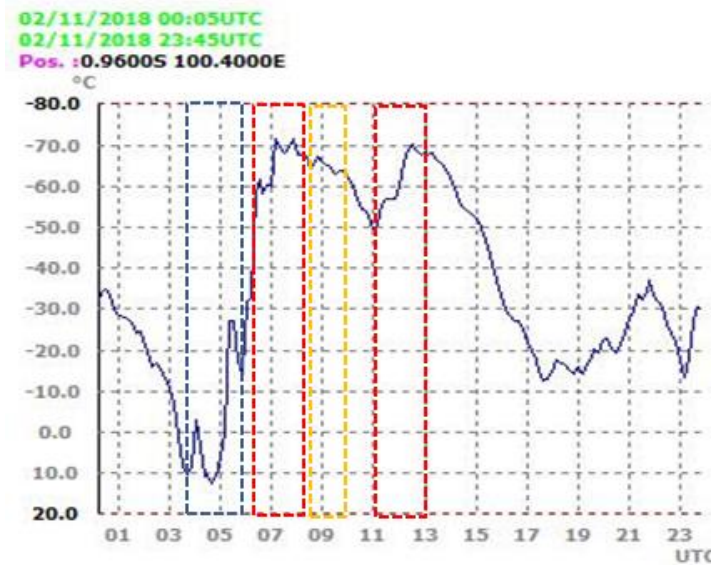

Gambar 6. Citra IR time series tanggal 2 November 2018 
Berdasarkan grafik deret waktu (Gambar 6) di wilayah Padang tanggal 2 November 2018, terlihat pola pertumbuhan awan mulai terbentuk pada saat beberapa jam sebelum terjadinya hujan lebat. Pembentukan awanawan konvektif mulai terlihat sekitar pukul 05.00 UTC, kemudian bertahan dan puncaknya pada pukul 08.00 UTC sebesar $72,5^{\circ} \mathrm{C}$. Terjadi kenaikan suhu sementara pada pukul 10.00 UTC dan terjadi penurunan suhu kembali secara signifikan pada jam 11.00 hingga $12.50 \mathrm{UTC}$ sekitar $-70{ }^{\circ} \mathrm{C}$ yang mengindikasikan pada saat itu terjadi pertumbuhan awan-awan konvektif seperti awan cumulonimbus. Kemudian, pada jam 13.30 UTC suhu puncak awan mengalami penurunan, yang artinya pembentukan awanawan konvektif sudah mulai tahap peluruhan dimana di wilayah Padang dan sekitarnya pada saat jam tersebut awan-awan yang terbentuk adalah awan menengah yang dapat menghasilkan hujan dengan intensitas ringan.

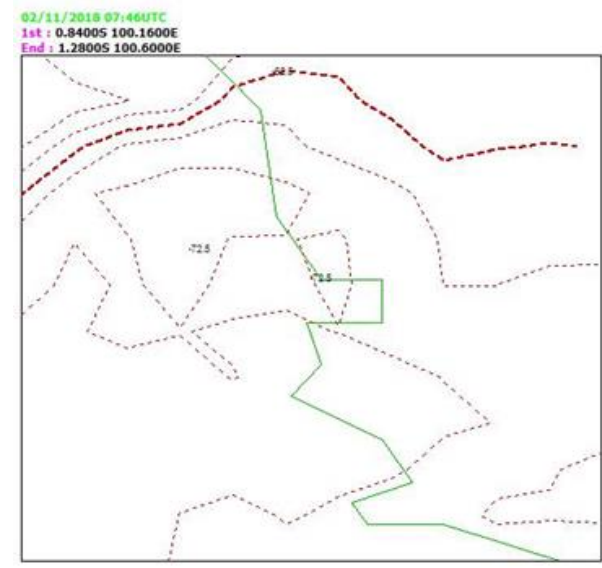

Gambar 6. Citra IR contour tanggal 2 November 2018

Berdasarkan gambar kontur awan di atas dapat dilihat bahwa suhu puncak awan di wilayah Padang dan sekitarnya mencapai $72.5^{\circ} \mathrm{C}$ dan cakupannya merata di wilayah Padang dan sekitarnya, sehingga mengindikasikan bahwa awan-awan yang terbentuk di wilayah tersebut adalah awanawan dingin yang merupakan awan cumulonimbus. Awan tersebut dapat menghasilkan hujan ringan hingga hujan dengan intensitas yang sangat lebat.

\subsection{Analisis Evolusi konvektif}

Berdasarkan output produk radar CMAX terlihat pola reflektivitas $45-60 \mathrm{dBZ}$ mulai muncul di pesisir Kota Padang pada pukul
06.00- 07.00 UTC. Hal ini menunjukkan adanya pertumbuhan awan konvektif di wilayah tersebut. Pada pukul $08.00-09.00$ UTC, pola reflektivitas cenderung kisaran 5 35 dBZ di wilayah pesisir Kota Padang, hal ini menunjukkan awan awan konvektif yang telah terbentuk pada pukul 06.00 UTC telah luruh menjadi hujan dengan intensitas sedang-lebat.

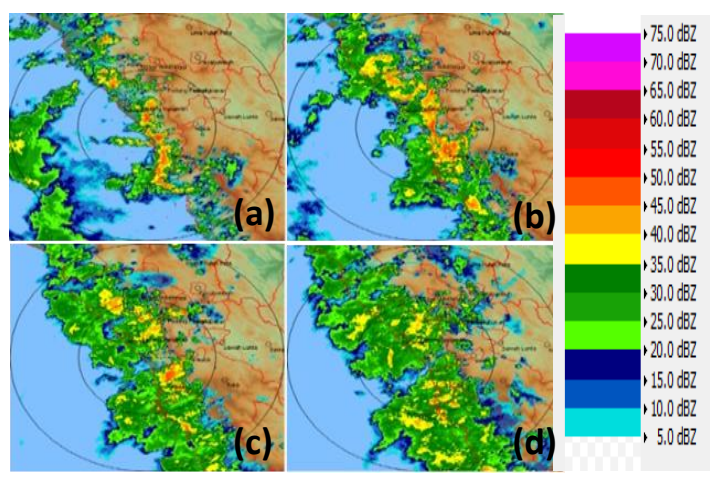

Gambar 7. Produk Radar CMAX pukul (a) 06 UTC, (b) 07 UTC, (c) 08 UTC, (d) 09 UTC

Berdasarkan pola pertumbuhan awan yang dihasilkan produk CMAX pada gambar 7 dilakukan analisis secara vertikal pada pukul $06.00-07.30$ dengan produk VCUT. Hasil ouput produk seperti yang ditunjukkan pada Gambar 8 . Pada pukul $06.28-06.38$ UTC terlihat adanya pola reflektivitas $35-45 \mathrm{dBZ}$ bergerak keatas. Hal ini menunjukkan pada pukul tersebut terjadi updraft pada awan di wilayah pesisir kota Padang. Pada pukul 06.48 UTC terlihat adanya pola reflektivitas 35-45 dBZ bergerak ke atas dan ke bawah. Hal ini menandakan beberapa tetesan awan di puncak telah jenuh dan turun ke permukaan. Pada pukul 07.18 UTC nilai reflektivitas secara vertikal cenderung 25 - 35 dBZ, hal ini menunjukkan awan konvektif telah luruh pada pukul 07.18 di wilayah pesisir Kota Padang.

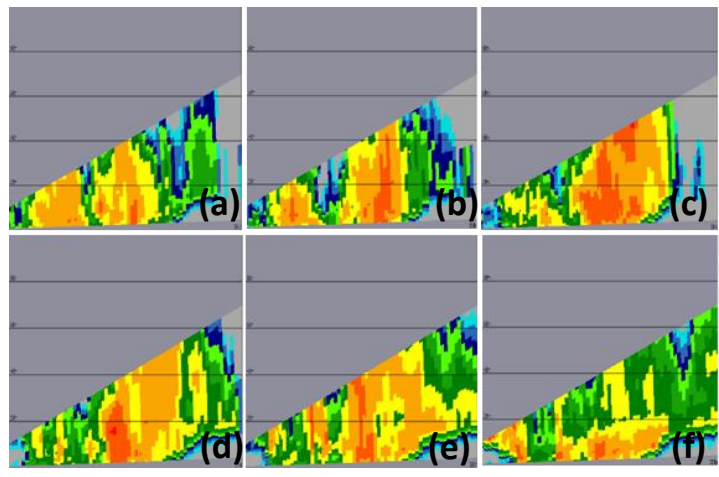

Gambar 8. Produk Radar VCUT pukul (a) 06.28 UTC, (b) 06.38 UTC, (c) 06.48 UTC, (d) 06.58 UTC, (e) 07.08 UTC, (f) 07.18UTC 


\section{KESIMPULAN}

Berdasarkan hasil dan pembahasan dapat disimpulkan bahwa pertumbuhan awan hujan yang mengakibatkan hujan dengan intensitas lebat di wilayah Kota Padang pada tanggal 2 November 2018 dipengaruhi skala global yaitu SST dan skala regional yaitu gradien tekanan dan pergerakan angin di lapisan 850 $\mathrm{mb}$. Pola shearline dimana komponen zona arah lintasan angin yang mengalami perubahan secara tiba-tiba yang sejajar dengan angin horizontal dan daerah tekanan rendah yang menimbulkan konvergensi di pesisir kota Padang. Nilai transport uap air yang cukup tinggi yaitu kisaran antara 700$1100 \mathrm{Kg} / \mathrm{ms}-1$ pada lapisan 1000-300 mb. Hal ini didukung dengan analisis penginderaan jauh menggunakan citra satelit Himawari-8 kanal IR dengan suhu puncak awan sebesar -72,5 0C pada pukul 07.10 dan produk radar CMAX dengan nilai reflektivitas pada 45-60 dBZ pada pukul 06.00 - 07.00 UTC di wilayah pesisir Kota Padang.

\section{UCAPAN TERIMA KASIH}

Penulis mengucapkan terima kasih kepada pak Paulus Agus Winarso dan pak Jusa Sujana selaku dosen pembimbing, seluruh taruna STMKG, Subbid Radar dan Satelit BMKG Pusat yang telah membantu dan memberikan akses data untuk menunjang penelitian ini.

\section{DAFTAR PUSTAKA}

Tjasyono HK, Bayong., 2008, Meteorologi Terapan, Penerbit ITB, Bandung

Dua orang tewas akibat banjir bandang di Padang, 2018. Detik, 2 November:18

Nababan, M., 2014, Studi Kejadian Bencana Banjir Berdasarkan Karakteristik Awan dan Hujan di Wilayah Jakarta, Skripsi, Program Sarjana Terapan Meteorologi, Sekolah Tinggi Meteorologi Klimatologi dan Geofisika, Jakarta.

Schowengerdt, R., 2006, Remote Sensing: Models and Methods for Image Processing, Academic Press.

Marjuki, 2007, Analisis Data Radar Cuaca Menggunakan Jaringan Syaraf Tiruan, Jurnal Meteorologi dan Geofisika, 3, 3.
Mahfiroh, 2017, Kajian Pemanfaatan Data Citra Satelit Himawari-8 Untuk Mendeteksi Awan Signifikan dari Awan Cumulonimbus, Skripsi, Program Sarjana Terapan Meteorologi, Sekolah Tinggi Meteorologi Klimatologi dan Geofisika, Jakarta.

Persson, A., dan Grazzini, F., 2007, User Guide to ECMWF Forecast Products, ECMWF, United Kingdom.

Anggoro, D., 2007, Kajian Waktu Hidup dan Pergerakan Awan Konvektf Berbasis Citra Radar dan Model ECMWF, Skripsi, Program Sarjana Terapan Meteorologi, Sekolah Tinggi Meteorologi Klimatologi dan Geofisika, Jakarta.

Wardoyo,E., 2011, Materi Radar Produk Gematronik, Training Radar Cuaca. Badan Meteorologi Klimatologi dan Geofisika, Jakarta.

BMKG, 2016, Pedoman Operasional Penginderaan Citra Satelit Cuaca, Badan Meteorologi Klimatologi dan Geofisika, Jakarta.

BMKG, 2014, Data satelit BMKG, Ftp://satelit.bmkg.go.id/, diakses tanggal 2 November 2018. 